\title{
$\mathrm{NO}_{2}$ 와 $\mathrm{N}_{2} \mathrm{O}_{4}$ 사이의 평형에서 압력의 영향에 관한 실험의 문제점 분석 및 개선
}

\author{
강응규 ${ }^{*}$ 강성주 ${ }^{*}$ \\ 공항고등학교 \\ 한국교원대학교 화학교육-가 \\ (2003. 2. 11 칩수)
}

\section{An Analysis and Improvement of the Experiment about the Effect of Pressure on the Equilibrium of the $\mathrm{NO}_{2}-\mathrm{N}_{2} \mathrm{O}_{4}$ System}

\author{
Eung-Gyu Kang and Scong-Joo Kang* \\ ${ }^{\dagger}$ Kongheng Ifigh School. Stonl 157-850. Nonea

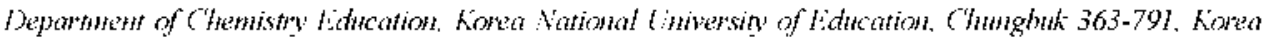

(Received February 11.2003)

\begin{abstract}
요 약. 이 연구에서는 $2 \mathrm{NO}_{2} \longrightarrow \mathrm{N}_{2} \mathrm{O}_{1}$ 계의 덩힝에 끼치는 압력의 영항운 색깔 변화를 통해 관찰하는 실험과 관

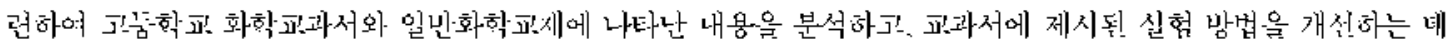

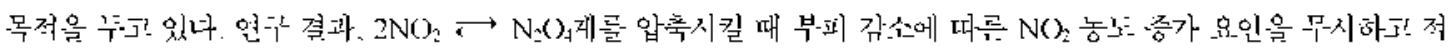
갈섹이 엷어지는 것으로 기순하고 있고 압축 시 일어나는 현상돌의 원인을 해석하는 테 오류가 있었다. 따라서 이론 적인 연구를 도데로 $2 \mathrm{NO}_{2} \rightleftarrows \mathrm{N}_{2} \mathrm{O}_{4}$ 계를 압축할 대 익어나는 색깔 변화와 온도 변화를 싱향적으륻 측싱하여 비교함 으른써 운바른 해석을 제시하였다. 뜬한. $2 \mathrm{NO}_{2} \rightleftarrows \mathrm{N}_{2} \mathrm{O}_{1}$ 계의 압축 시. 부피 갑소에 마흔 $\mathrm{NO}_{2}$ 능도 증가 효과를 내제 하고 순수한 병형 이돟에 마른 색깔 년화만은 관찬할 수 있는 개선된 실혐 방법은 제시하였다.
\end{abstract}

주제어: 횡형 이돟. $\mathrm{NO}_{2}, \mathrm{~N}_{2} \mathrm{O}_{4}$. 합력의 영햠

\begin{abstract}
The purpose of this research was to analyze and improve the experiment. observing the color change under compression on the equilibrium of $2 \mathrm{NO}_{2} \longrightarrow \mathrm{N}_{2} \mathrm{O}_{1}$ system. deseribed in high sehool and general chemistry textbooks. Chemistry textbooks described that the reddish brown color got lighter on the compression of $2 \mathrm{NO}_{2} \longrightarrow \mathrm{N}_{2} \mathrm{O}$, system. This misinterpretation was due 10 no consideration of $\mathrm{N}()_{2}$ concentration increase by the volume decrease. In order to propose a correct interpretation, the ehanges of color and temperature on compression were quantitatively measured and compared with theoretical studies. In addition, an improved experiment. excluding the eflect of $\mathrm{NO}_{2} \mathrm{con}^{-}$ centration increase. was proposed to observe only the wolor change of the net equilibrium shit
\end{abstract}

Keywords: Equilibrium Shitt. $\mathrm{NO}_{2} . \mathrm{N}_{2} \mathrm{O}_{1}$. Effect of Pressure

\section{서 론}

\section{연구의 필요섬과 목적}

고등학교 화학 II 교과 과청 춤에서 화학 형형은 학 셍들이 이해하기 어려워하눈: 던원 줌의 하나로 화학 평
형의 개념을 석명하기 위해 예러 가지 신헌. 모형. 킴퓨 터 시뮬레이션을 이용한 동영상들이 개발 연 두되어지 고 있다.' 화학 형형의 이똥을 시각적으론 버여쭈기 위 한 방법들도 다양하게 연구녜어 왔는데. 프 충 $2 \mathrm{NO}_{2}$ $\longrightarrow \mathrm{N}_{2} \mathrm{O}_{1}\left(\Delta \mathrm{H}^{\circ}--57.2 \mathrm{k} . \mathrm{T}\right)$ 계는: 온도나 압력의 년화에 
따-라 뉚게 평형이 이동하기 때문에 매.우 유홍하고 호열

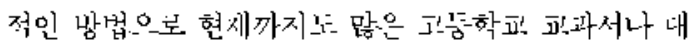
학 교재에서 다루어지고 힜다

그런뎨. $2 \mathrm{NO}_{2} \rightleftarrows \mathrm{N}_{2} \mathrm{O}_{1}$ 계를 이양한 실힘은 온도에 의한 평형 이동은 설밍하는뎨 있어서는 뚜렷한 색깔 변 화 때문에 매·우 윢용한 낭법이지난. 압력에 의한 켱형 이동을 섬병하는례 있어서는 신제 신험 결과와 기존의 기ㄴㅘㅘ서나 신험서에서 제시하거 있는 색깐 변화가 나그 기 때눈-에 교사가 정흭한 지식은 갖고있지 않으년 훈란 은 고래하기 웝다. 죽. $2 \mathrm{NO}_{2} \rightleftarrows \mathrm{N}_{2} \mathrm{O}_{4}$ 계를 압혹시키면 압촉 식후 적찰색이 진해겼다아 시간이 지나년서 엮어 지지난 압훅 적에 비해서 진한 적각세이 힌어지는네,

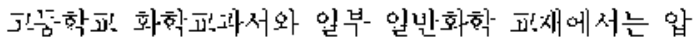
훅 전에 비해 적갈세이 엷어지는 것으로 기손하고 있나. 이에 대해 Yang $\frac{2}{1} 2 \mathrm{NO}_{2} \rightleftarrows \mathrm{N}: \mathrm{O}_{4}$ 계에 압력을 가하-면 부피 갑소에 의해 $\mathrm{NO}_{2}$ 의 낭도가 증가하여 색깔은 진하 세 하는: 효과와 핚께 평형이 $\mathrm{N}_{2} \mathrm{O}_{1}$ 쭉으로 이퐁하여 색 낍:을 엷게 하는 호과가 동지에 나타나는테, 북피 변화 에 의한 호과가 평형 이동에 의한 호파보나 커나곤 하 었나. 또한, 깉은 국기의 줖사기에 적각새을 띠는 $13 r=$ 을 넣은 섯을 비교 시료론 하여 압축 시의 색깔은 비교하 면 됭형 아돟이 읶어나지 않는 $\mathrm{Br}$ 에 비해 $2 \mathrm{NO}_{2} \rightleftarrows \mathrm{N}_{2} \mathrm{O}_{1}$ 계의 색깔이 상대적으론 얶게 나타나므룬 형형의 이동 을 섹깜 변화로 관칠할 수 있나고 하었나

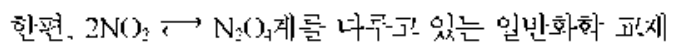
논은 $2 \mathrm{NO}_{3} \longrightarrow \mathrm{N}_{2}\left(\mathrm{O}_{4}\right.$ 계의 압축 직후 적각섹이 신해,지는 섯음 부푀 값소 때녹이며. 시간이 지나뗜서 다시 얿어지 녹: 섯은 압력에 의한 횡형 이동 현상으른 설명하고 힜다. 박면. Lecnsoli은 이론적인 칩근은 동해 평형의 이완시간

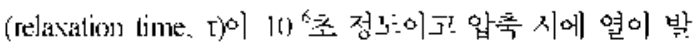
생하기 때문에 압축 직후에 적각색이 식해지는 것은 북-iㅣ 각소와 열 때문이며, 나시 엷어지는 겻은 계가 나시 냉각 뇌면서 읶어나눅: 온도에 의한 횡형 이퐁이라고.지적하고 있다.

마라서. 이 연구에서는 고등학교 화학교라서와 익반 화학 교재의 네용은 분선하고. Leenson의 이폰적 해석 을 신험을 봉해 규녕하거자하며, $2 \mathrm{NO}_{2} \longrightarrow \mathrm{N}_{2} \mathrm{O}_{1}$ 계를 이용한 신험의 개선 낭안을 무섹하거자 한나.

\section{연구 내욜 및 방법}

\section{연구내용}

1. 현행 제 6 차 닟 제 7 차 표'육과정에 의힌 고늠학표' 화
학II 기년서와 일반화학 고새에 제시퇸 $2 \mathrm{NO}_{2} \longrightarrow \mathrm{N}_{2} \mathrm{O}_{4}$ 게의 압릭에 따른 컹형이동에 관한 실혁 내옹과 결과 및 설밍은 분선한다.

2. $2 \mathrm{NO}_{2} \rightleftarrows \mathrm{N}_{2} \mathrm{O}_{4}$ 계에 압력을 가할 때 일어나는 색 깔과 온도의 면화를 징량적으론 축싱하여. 윤바른 해선 을 제시한나.

3. 하돠서서에 제시퇸 $2 \mathrm{NO}_{2} \longrightarrow \mathrm{N}_{2}()_{4}$ 신혁의 개신 방 안을 모색한나.

\section{분석 대상 교과서}

이 연구에서는 12 총의 제6차 교육과싱 고등학교 화 학 II 피돠서와 5 종의 제 7 차 표'유과정 넌듬학표! 화학 [I 과과서 그리고 넝ㅈㅇㅇㅇㅢ 일난화학 피채를 분석 자효로 하

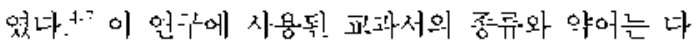
움과 같다.

(1) 6차 교육과심 화학 $\operatorname{II}(12$ 종 $)$

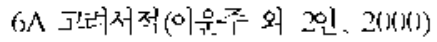

6]3 파학자-(요제직 외 ㄱ인, 1997)

$6 C$ 금성춤한사-(김시중 외 f인. 1999)

$6 \mathrm{D}$ 형선출판(송호봉 외 1인. 2000)

$6 \mathrm{E}$ 지학사(바기원 외 1인. 1997)

6F 두산돟아(소현수 외 난이. 1996)

6(3 청문각(ㅇ:수동 외 오인, 20)(1)

6II 동아서저정파도 외 인, 2000)

6I 박엉자(박배주 외 2인. $200(0)$

$6 \mathrm{~T}$ 교학사(이원식 외 3 인. 2000)

$6 \mathrm{~K}$ 천재교육(우규환 외 1인. 1997)

6L 한샘출판(최병순 외 3인. 1998)

공 7 차 피유와과정 화학 $\operatorname{II}(5$ 종)

$7 \wedge$ 금성형한사(서정쌍 외 6인. 2002)

$7 \mathrm{~B}$ 대한교과서(이닉환 외 7인. 20012)

$7 \mathrm{C}$ 중앙교육-진흥연구소(우규환 외 5 인. 2(012)

7D 청는-각(여수동 외 7인. 2002)

7f: 친채피'육(긲희중 외 5인, 20102)

'곤' 일빈화학교재(4종)

UA Chenical Demonstrotions (Slakilastliri. 1985)

UB (General Chemiston (tthins. 1989)'

UC Chemistry (Zumdahl \& Zumdahl. 2000)

(J) Chenisirn (Brown ef at. 20001)" 


\section{실 험}

\section{시약 및 시료}

실험에 사용한 $\mathrm{NO}_{2}$ 기체는 고등학교 화학교과시나 고등학교 화학식험과 관련된 연구 눈-헌 ${ }^{8-10}$ 에서 일반적 으로 제시하거 있는 진한 질산퐈 다리의 반응을 이용하 여 준비하었다. 거눈ㄴㄷㄴㅇㅢ $\mathrm{NO}_{2}$ 기체를 인기 위하여 기 손의 낭법을 개선하었다. ${ }^{11}$

\section{색깔의 점량적 비교}

$2 \mathrm{NO}_{2} \rightleftarrows \mathrm{N}_{2} \mathrm{O}_{1}$ 계를 압축시첬은 때. 색깔이 숙간적 으로 진해졌나가 나시 엷어지기 때문에 압훅 전돠 압훅 후 일정 시간이 홀렸을 때의 세각의 신하기를 유안으로

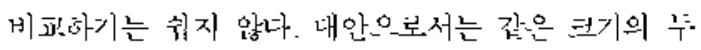
개의 주사기에 $\mathrm{NO}_{2}$ 시로 를 넣고 하나는 압훅하지 않고 다른 하나는 압혹하면서 두 추사기의 색깔은 비교하는 방넙을 사용한 수 있다.

이 연-1에서는 $2 \mathrm{NO}_{2} \longrightarrow \mathrm{N}_{2}\left(\mathrm{O}_{1}\right.$ 게의 압축 적후의 식 낀을 정량적으노 비표하기 위해 색깐을 수치화 함 수 있는 장치를 $/ \mathrm{ig}$. 1과 깉이 고안하여 시용하였나.

이 장지는 $\mathrm{NO}_{2}$ 가 가시광선 영역 선반에서 강하제 홉 수하는 반면 $\mathrm{N}_{2} \mathrm{O}_{1}$ 는 가시 광선운 홉수하지 않으므론.2 가시광선의 양은 츤청하는 조도계(INS DX-100)를 이용하여 구성하헜ㅆㅆㄷㅏ. 이 장치에서 광원은 꼬나 적가 $(6.5 \mathrm{~V}, 150 \mathrm{~mA})$ 를 사용하었으명, 광윈의 열에 의한 온-

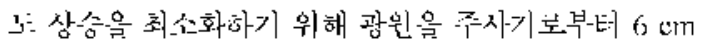
거리에 설치하였고. 압촉 시 수사기 밥으른의 기체 누 촐을 막기 위해 피스든 표면에 실리콘 느리스를 칠하였 다. 쭈사기는 학교 실험실에서 읶반석으론 사용한ㄴㄴ $50 \mathrm{~mL}$ 유러 좃사기를 이용하었으영. 주사기, 광센서, 광윈은

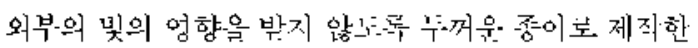

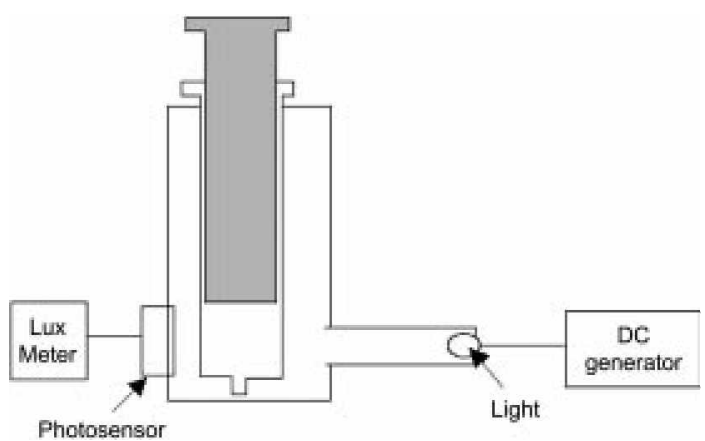

Fig. 1. Instrument for the measurement of lux.
들에 맞추어 언결하었나. 시료의 초놀 촉정은 $\mathrm{NO}_{2} 40$

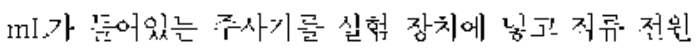

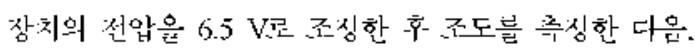
기체의 부피를 12 로 압혁한 -후 계가 횡형에 도날하였 을 내(잗ㄷㅗㅏ 변하지 않을 내) 다시 자도를 른싱하였다.

\section{압축 시의 온도 변화 촉정}

계를 압축시킬 때 밪생 하는 열은 윓게 줃위로 빠겨나 가기 때눈-에 읽반적인 온도계론는 온도 변회를 싱확히 측성하기 어렯다. 마라서. 이 실험에서는 기체의 온도 를 륵싱하는데 사용하느ㄴㅡㅗ 온도 변화에 데해 반응섬이 큰 열전쌍(themocoulpe. I):R Iir: K-type)을 이용하였 으며. 실험 장치는 $\mathrm{l} / \mathrm{g} .2$ 와 같나. 피스논은 테프른 시 질로 제자하였다. 신험은 컹형 이동이 일어나지 밚는 공기를 비교 시로론 하여. 같은 크기의 두 쑤사기에 삭 각 공기와 $\mathrm{NO}_{2}$ 시로를 $40 \mathrm{~mL}$ 씩 넣고 부피를 반으르 압촉 시쳤은 때 최고 온도를 흑칭하였다.

온-1츨 촉정은 동일 시료에 대해 예러 번 압축을 반복

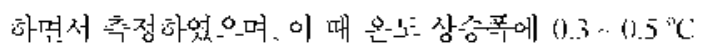
정 너의 펀차가 있는테, 이것은 기체를 합축시키는 속도프. 가 매 실힘마다 약간싹 달랐던데 뚜된 요인이 있는 것 으론 싱삭된다.

\section{실험 방법의 개선}

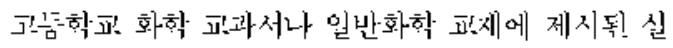
험 낭법은 $2 \mathrm{NO}_{2} \longrightarrow \mathrm{N}_{2}\left(\mathrm{O}_{4}\right.$ 게를 압훅할 때 색길의 변화 를 추사기의 흑띤에서 관찰하년데. 이 겅우에는 부피 간소에 마른 $\mathrm{NO}_{2}$ 낭도 증가 효과늘 배제시킭 수 없어

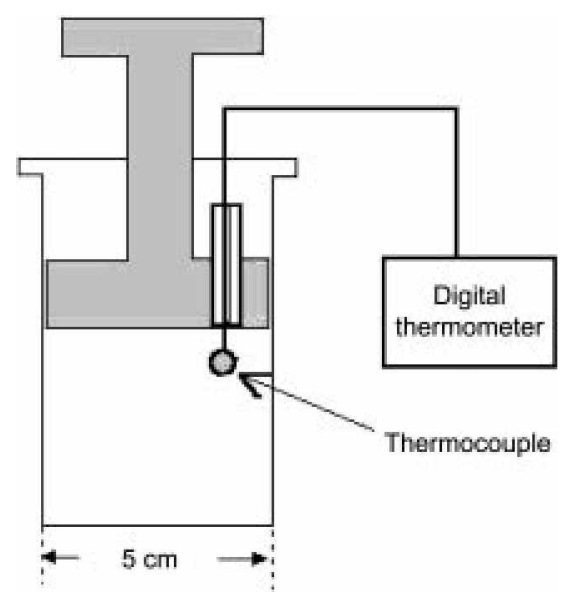

Fig. 2. Instrument lor the measurement of temperature. 


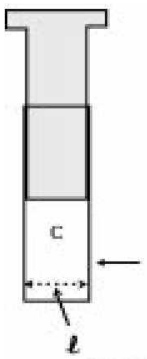

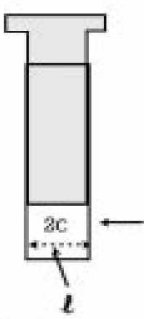

(a) side view

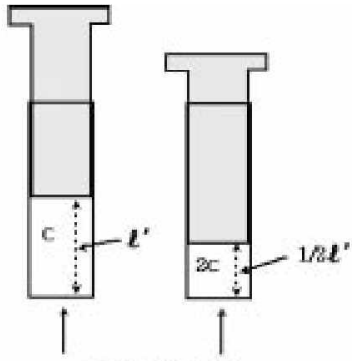

(b) front view
Fig. 3. Dependence of absonplion by lhe view direction.

켱형 이동응로 예상한 격퐈와 닌-대로 나타나게 뒥나. 하지난 섹깐 변화를 피스통을 압훅하는 낭향에서 관칠 한나면 북iㅣ 각스에 따론 N() 농는 증가 호롸를 배제 시칠 수 있고. 뼝힝 이동에 마른 색깔 년화민운 관찬한 수 힌세 된다. 족. 계를 합훅하여 부피가 갑소할 때. Fig. 3의 (a)와 같이 측면에서 관찬할 겅우는 시로를 둥과하 는 빛의 통과긴이(1)에는 변화가 잆곤 농ㄴㄱㄱㄱ 2배로 증 가하기 때문에. Beer의 법칙 $\Lambda-\varepsilon c$ 에서 홈광 $1: \Lambda$ 가 2 배로 증가하여 적갈색이 2배로 신해신나. 난면 / $/ \mathrm{gg}$. 3 의 (b)와 같이 피스돈을 압축하는 방향에서 관찬하면 농도가 2배로 증가하는: 반면에 통과길이는 2내 갑소하 기 때눈-에 부피 갑소에 의한 홉광도의 변화는 생기지 않게 된나.

이러한 원러를 이용하여 신험 낭법을 개신하기 위해 $\mathrm{lig}$. 4화 각:은 장치를 제작하었나. 그릭에서 신런너는 욱안으로 색깔 년화를 관찬하기 위해 유러론. 피스돈은

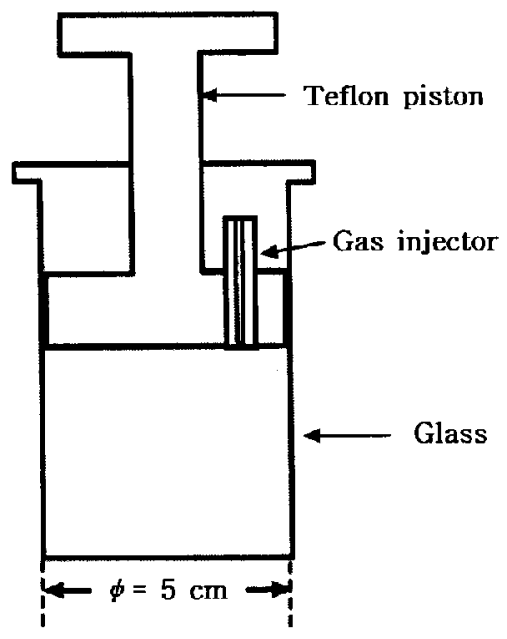

Fig. 4. The improved instrument.

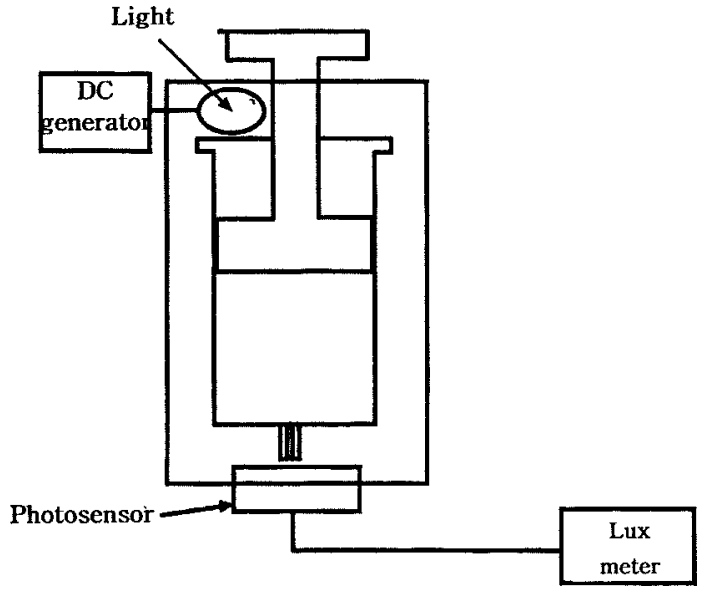

Fig. 5. The measurement of lux from front view.

기체 수입구를 만들고 똔한 색깔 년화의 관찬을 숑이하 제 하기 워해 테프론으로 제삭하었다. 뜬한. 압축 시 기 체의 누출운 막기 위해 피스톤에 실리콘 $O$-ring옾 부착 하였으며 실헉 시에는 회스논의 윈홯한 운직임콰 기체 의 눟축을 낭지하기 위해 실러쿤 그리스롤 칠하였나.

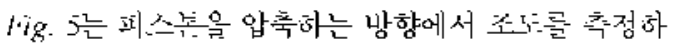
기 위해 고안한 징치로. 추사기의 실린디와 피스돈은 즈도 측싱운 위해 부밍한 유리로 제삭하였고. 실린디 워에 광원(고나 선구. 6.5 V. $150 \mathrm{~mA}$ )은 고싱시키고 광

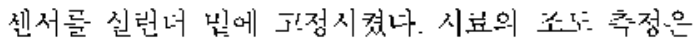
$\mathrm{Fg}$. 1의 장치를 이용한 신헊과 동일하게 하었다.

\section{연구 결과 및 논의}

\section{교과서 분석}

제 6 차 닟 제 7 차 표?육 과정 표과서에서 $2 \mathrm{NO}_{2} \longrightarrow \mathrm{N}_{2} \mathrm{O}_{1}$ 게를 이용한 탂가 확동- 내용과 탂구 확동에서 관착되는 결과를 초사하여 Toble 1에 정러하었다.

제6차 교욱 과싱에서는 7 총 $(6 \mathrm{~A} \cdot 6 \mathrm{G})$ 교과서에서 $2 \mathrm{NO}_{2} \rightleftarrows \mathrm{N}_{2} \mathrm{O}_{1}$ 계를 이용한 담구 환둥은 다루고 있고.

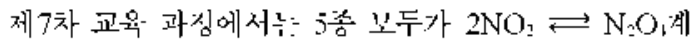

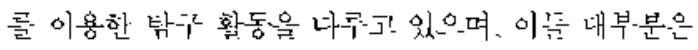
공봉적으로 압축 시에는 적갂식이 엷어지는 격과롤 제 시하고 있다. 또힌, 탂구 활동을 나국지 않고 있는 5종 의 교과서 $(6 \mathrm{H} \cdots 6 \mathrm{~L})$ 충 공ㅇㅇ $(6 \mathrm{H} .6 \mathrm{I} .6 \mathrm{~J})$ 의 교과서는 압 력에 따른 평헝 이동현상울설명하기 위해 $2 \mathrm{NO}_{2} \rightleftarrows \mathrm{N}_{2} \mathrm{O}_{1}$ 계를 이용하고 있으며. 공통석으로 압축 시에 석찰색이 엷어지는 것으로 기술하그 있다. 따라서, 수입 시간에 
Table 1 . Intuir activities of the effect of pressure on the equilibrium in the $2 \mathrm{NO}_{2}-\mathrm{N}_{2} \mathrm{O}_{4}$ ststem

\begin{tabular}{|c|c|c|}
\hline Textbook & Fxperimental Method & Results \\
\hline $6 \mathrm{~A}$ & Compression of the $\mathrm{NO}_{2}-\mathrm{N}_{2} \mathrm{O}_{4}$ mixture and observation of color change & The color of the sistem becomes lighter \\
\hline $6 \mathrm{~B}$ & " & $n$ \\
\hline $6 \mathrm{C}$ & $"$ & The color of the system becomes colorless \\
\hline $6 \mathrm{D}$ & $"$ & $n$ \\
\hline $6 \Gamma:$ & $"$ & No result presentatiot \\
\hline $6 \mathrm{~F}$ & Compression of the air $\mathrm{NO}_{2}-\mathrm{N}_{2} \mathrm{O}_{4}$ misture and observation of color change & The color of the sistem becomes lighter \\
\hline $6 C^{\circ}$ & $"$ & $n$ \\
\hline $611 \cdots 6 \mathrm{~J}$ & \multicolumn{2}{|l|}{ No inquiry activity } \\
\hline $7 \mathrm{~A}$ & \multicolumn{2}{|c|}{ Compression of the $\mathrm{NO}_{2}-\mathrm{N}_{2} \mathrm{O}_{4}$ mixiture and obsen ation of color change $\mathrm{l}$ he color of the sy stem becomes lighter } \\
\hline $7 \mathrm{~B}$ & $"$ & $n$ \\
\hline $7 \mathrm{C}$ & $"$ & $"$ \\
\hline $7 \mathrm{D}$ & $"$ & $"$ \\
\hline $7 \mathrm{E}$ & $"$ & No result presentation \\
\hline
\end{tabular}

Teble 2. Description of the $2 \mathrm{NO}_{2}-\mathrm{N}_{2} \mathrm{O}_{4}$ ssstem in general chemistry textbooks

\begin{tabular}{lc}
\hline \hline Description & Textbonk \\
\hline The color becomes lighter as the pressure ol the system increases & UA. UB \\
The color becomes darker right atter compression as the wolume ol the sistem decreases & UA ... UD \\
The color becomes dark, then light due to the cquilibrium shitt as a function of pressure & UA - UDD \\
\hline
\end{tabular}

담구 환동을 하는 겅우 실제로 관찬되는 현상과 다르기 매눈-에 교사. 학생 노두 혼란을 격운 수 있는 넌제짐이 있다. 또한. 땀구 햘동은 다룬 교과서의 겅우. 맙촉 식 후에 적갈섹이 신해지는 현상을 나룩근 있지 않기 때문 에 신제 탂구 활동에서 피시가 정화한 지식을 갖더 있 지 않을 경-운 학생홇에게 혼란을 초레함 수 있는 문제 짐이 있다.

한펵. 20여종의 잎반 화학 교재 및 실험서 중 $2 \mathrm{NO}_{2}$ $\rightleftarrows \mathrm{N}_{2} \mathrm{O}$, 계의 압력에 마른 색깔 면화를 다룬 4종의 교 재의 새옹을 분석한 결과를 Table 2에 정러하였다.

4 종 모구 압축 직후 섹긴이 식해지는 현상의 윈인을 북-피의 갂소로난 보도 있으며, 나시 색꺽이 엷어지는 섯올 압력에 의한 횡형 이퐁 현상으로 설밍하고 있다. 특히 UA와 UB는 새론운 헝형에 도달한 후의 색깔이 압촉 천너다 엮어진다고 기술하고 있다.

\section{압력에 따른 색깔 변화의 정량적 비교}

$2 \mathrm{NO}_{2} \rightarrow \mathrm{N}_{2}\left(\mathrm{O}_{1}\right.$ 계의 북피를 반으로 압축핚 때 일어나 늑: 색깔 년화를 싱챵적으로 비교하기 위해 Fig. 1의 창치 를 이용하여 조도를 축청한 결과를 Table 3에 나타네었다.

조도가 108 lux에서 931 1ux른 갑소한다는: 것은 계의 적각섹이 신해직나는 것을 의미하므로 Tahte 의 격과
Table 3. The change of lux before and atter compression

\begin{tabular}{cc}
\hline \hline Before & Atter \\
\hline 108 & 92.94 \\
\hline
\end{tabular}

로부ㄱㅕㅕ $2 \mathrm{NO}_{2} \longrightarrow \mathrm{N}_{2}\left(\mathrm{O}_{1}\right.$ 계에 압럭을 가하면 적갚새이 신해신나는 사신을 알 수 있나. 이러한 결과는 거늠학 교 화학교과서에 제시된 내용과 싱반된다. 압력을 가하 떤 적갈색이 진해지는 것음 압축 시에 압력의 증가에 마론 헝형 이동에 의한 $\mathrm{NO}_{2}$ 농도의 감소녀다눈: 압훅에

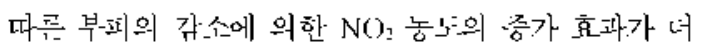
코다포 적명함 수 있나.

\section{압축 시의 온도 변화}

이상기체가 단역 가멱석인 압축은 할 때 익이 행해.지 고. 이 읶에 의해 계의 온도 변화가 익어나세 된다. 이 때 온-5:와 북피간에는 나음과 간은 식이 성립됙나. ${ }^{5}$

$$
r_{s} T_{s}^{r}-I T_{f} \quad c-\frac{C_{x, m}}{R}
$$

(는: 처음 상태. $\mathrm{f}$ 는 최종 상태. $\mathrm{C}_{\mathrm{V}, \mathrm{m}}$ 은 익침 부피에 서의 놀 멸영량)

식 (1)을 변혐하멱 나음 식 (2)이 엄어친다. 
Table 4. Variation of temperature ("C) on compression

\begin{tabular}{cccc}
\hline \hline Sample & Initial & Maximum & Increment \\
\hline $\mathrm{Nir}$ & 26.6 & $30.6 \cdots 30.9$ & $4.0 \cdots 4.3$ \\
$\mathrm{NO}$ & 26.6 & $31.6 \cdots 32.1$ & $5.0 \cdots 5.5$ \\
\hline
\end{tabular}

$$
f_{f} \neq\left(\frac{l_{i}}{t_{f}}\right)^{l \cdot r}
$$

익원사 기체의 겅우 $\mathrm{Crm}-3 \mathrm{R}$ 2. 비선형 다원사 기체 의 겅우 $\mathrm{C}_{\mathrm{n}, \mathrm{m}}-3 \mathrm{R}$ 이다. $2 \mathrm{NO}_{2} \rightleftarrows \mathrm{N}_{2} \mathrm{O}_{4}$ 계를 뙹힝 이동 이 읶어나지 않는: 이상 기체론 가싱하고 $298 \mathrm{~K}$ 에서 부 피를 12 배로 단열 가역 압훅시킨나고 학 때 시 (2)을 이뵹하여 온거는 변화를 게산해보면 $\mathrm{T}_{\mathrm{t}}-2982^{13}-375.5$

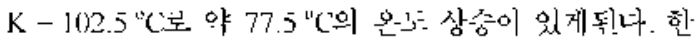
펵. Lwanson은 $2 \mathrm{NO}_{2} \rightleftarrows \mathrm{N}_{2} \mathrm{O}_{4}$ 계의 뙹힝 이퐁운 고려 하여 1 2부피론 압훅 시 $13 \mathrm{~K}$ 정도의 온도 상승이 힜은 것으로 예촉하었다. 프레나 실제 실혐에서는 가역 과싱

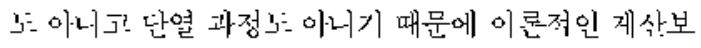
나는 적은 온번 상영이 있을 것은로 에상할 수 있나

$T a b h^{\prime}$ 느는 공기와 $2 \mathrm{NO}_{2} \longrightarrow \mathrm{N}_{-}()_{4}$ 게를 12 북표로 압 혹;한 때 익어나는 온도 년화를 측징한 것으론. 단역 가 역 압혹 과정으로 가싱하여 예싱한 온도 변화너다는 매 우 삭지민 수녹한만학 온도 상승이 익어넜으며. 텅형 이동이 일어나지 않는 공기보나 $2 \mathrm{NO}_{2} \longrightarrow \mathrm{N}_{2}()_{1}$ 게에 서 온고응상승폭이 커게 나타난 것을 알 수 있나.

온고은 변화에 관힌 신험 격과에서 공기보나 열용랑이

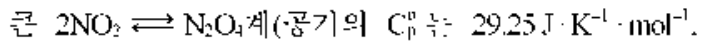
$\mathrm{NO}_{2}$ 의 $\mathrm{C}_{1}^{\circ} \div 37.62 \mathrm{~J} \cdot \mathrm{K}^{-1} \cdot \mathrm{mol}^{-1} \cdot \mathrm{N}_{2} \mathrm{O}$ 의 $\mathrm{C}_{1}=77.24$ $\mathrm{J} \cdot \mathrm{K}^{-1} \cdot \mathrm{mol}^{-1}$ )에서 온도 상승곡-이 약간 크세 나타났는데, 난약 $2 \mathrm{NO}_{2} \longrightarrow \mathrm{N}_{2}\left(\mathrm{O}_{1}\right.$ 계의 열용량이 공기와 간나거!

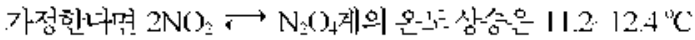

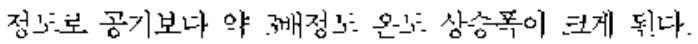
여기서 온도 계산윽 $\mathrm{NO}_{2}$ 와 $\mathrm{N}_{2} \mathrm{O}_{4}$ 의 역 용향이 은도에 부 관하다고 가청하고 $2 \mathrm{NO}_{2} \rightleftarrows \mathrm{N}_{2} \mathrm{O}_{1}$ 계의 역-영항은 압축 식후의 조성비를 고려한 $\mathrm{NO}_{2}$ 와 $\mathrm{N}_{2} \mathrm{O}_{1}$ 의 횡규 멱용향 $\left(65.74 \mathrm{~J} \cdot \mathrm{K}^{\prime} \cdot \mathrm{mol}^{\mathrm{l}}\right)$ 을 이용하였나. 이와 갆이 공기보 나 온보 상승폭이 크나는 것은 $2 \mathrm{NO}$ 그 $\longrightarrow \mathrm{N}_{2}()_{4}$ 계의 압

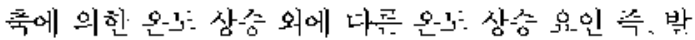
역 박응 $\left(\mathrm{N}_{2} \mathrm{O}_{4}\right.$ 의 셍성)이 읶어닜다늑: 섯은 의미한다. 마 라서. 압촉 식후에 압력에 의한 $\mathrm{N}_{2} \mathrm{O}_{1}$ 쪽,으론 평형 이동

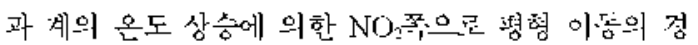
징 관계로 해석 할 수 있나.

\section{평형 조성 계산올 통한 실험 결과의 해석}

$2 \mathrm{NO}_{2} \longrightarrow \mathrm{N}_{2}\left(\mathrm{O}_{4}\right.$ 계의 켱형상스는 보통 나을 식가 간 이 나타낸다.

$$
\kappa_{p}-\frac{P_{\mathrm{NO}}^{2}}{P_{\mathrm{NO}_{2} O_{1}}}
$$

익싱 온도에서 $2 \mathrm{NO}_{2} \rightleftarrows \mathrm{N}_{2} \mathrm{O}_{4}$ 계가 뻥힝 상태에 힜 을 매. 계의 조성은 식 (3)과 $\mathrm{P}_{\mathrm{t}}-\mathrm{P}_{\mathrm{W}_{2}}+\mathrm{P}_{\mathrm{x}_{2} \mathrm{U}_{1}}$ 관계를 이 용하여 유도한 식 (4)에 의해 윕체 구한 수 힜다.

$$
\begin{gathered}
P_{\mathrm{NO}_{2}}-\frac{\left(K_{p}^{2}-4 K_{p_{1}}\right)^{1 \cdot 2}-K_{P}}{2} \\
P_{N_{2} O_{+}}-P_{1} P_{W_{2}}
\end{gathered}
$$

그런녜 $2 \mathrm{NO}_{2} \longrightarrow \mathrm{N}_{2} \mathrm{O}_{1}$ 게의 압훅 시에 펑형 이동이 일어나 게의 전체 압력을 부-피 변화로부-터 워게 알 숭 없음ㅁㄷㅗ. I eenson은 압축 후의 계의 컹형 소성을 계산 하기 워해 이싱 기체 방싱식운 이뵹하여 다음과 같음 식운 유도하었다?

$$
n_{6}-n\left(\mathrm{NO}_{2}\right) \cdot 2 \mathrm{n}\left(\mathrm{N}_{2}\left(\mathrm{O}_{4}\right)\right.
$$

$\left(\mathrm{n}_{0}\right.$ : 게에 $\mathrm{NO} \mathrm{O}_{2}$ 난이 족체한나그 가정했을 때의 $\mathrm{NO}_{2}$ 의 몬 $-\hat{1})$

$$
\begin{aligned}
& P_{K O_{2}}-\frac{\left(K_{p}^{2}+8 R T K_{f}, \mathrm{n}_{s} / 1\right)^{1 / 2} K_{p}}{4}
\end{aligned}
$$

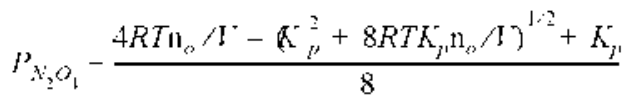

워 온도 년화 실험에서 얻어진 결과론부터 식 (4) (8)

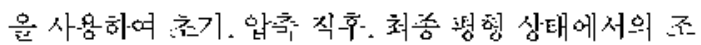
성을 게산학 수 있나. 가 상테에서의 초성을 계산하기 위해서는 먼저 각 온도에서의 평형 삼수 $K_{1}$ 값을 알아야

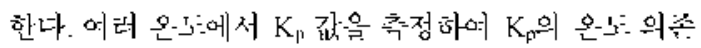

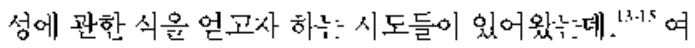
기서는: Leenson이 역역학 자모를 이영하여 유도한 식인 $\mathrm{K}_{\mathrm{p}}-\operatorname{cxp}(21.13-6880 \mathrm{~T})$ 를 이영하였다.

우석 초기 평형(압훅 적)의 $\mathrm{NO}$ 의 부분 압려 $\mathrm{P}_{\mathrm{NO}}$ 는 식 (4)을 이용하여 구하고. $\mathrm{N}_{2}\left(\mathrm{O}_{4}\right.$ 의 부분 압러 $\mathrm{P}_{2} \mathrm{\sigma}_{4}$ 는 초기 평형 상태의 적체 압러 $\mathrm{P}_{\mathrm{r}}$ 가 I $\mathrm{atm}$ 이므로 식 (5)을 이용해서 구하며. 이 매의 $\mathrm{NO}_{1}$ 와 $\mathrm{N}_{1} \mathrm{O}_{1}$ 의 돌수는 두 기 체를 이상 기체론 가침하여 $\mathrm{PV}-{ }_{\mathrm{NRT}}$ 관계를 이용하여 구하었다. 실험에서 $40 \mathrm{~mL}$ 의 시로를 사용헸으므론 고 기 평혐에서의 부피 $\mathrm{V}-0.04 \mathrm{I}$ 가 됙나나. 한면 12 부-피 
Table 5. Compositions at initial state, right after compression and final state

\begin{tabular}{|c|c|c|c|c|c|}
\hline \multirow{2}{*}{ Condition } & \multirow{2}{*}{$\mathrm{T}(\mathrm{K})$} & \multicolumn{2}{|c|}{$P^{\prime}(\mathrm{atm})$} & \multicolumn{2}{|c|}{$n$ (nol) } \\
\hline & & $\mathrm{NO}_{2}$ & $\mathrm{~N}_{2} \mathrm{O}_{4}$ & $\mathrm{NO}_{2}$ & $\mathrm{~N}_{2} \mathrm{O}_{4}$ \\
\hline Inivial state & 299.6 & 0.328 & 0.672 & $5.33 \quad 10^{-1}$ & $1.0910^{-4}$ \\
\hline líght atler & 304.8 & 0.578 & 1.412 & $4.6210^{-1}$ & $1.1310^{-3}$ \\
\hline Final slate & 290.6 & 0.478 & 1.433 & $3.89 \quad 10^{-1}$ & $1.1710^{-3}$ \\
\hline
\end{tabular}

(0.02 J.)로 압훅한 직후와 최증 평형 상테에서의 $\mathrm{NO}_{2}$ 와 $\mathrm{N}_{2} \mathrm{O}$ 의 부분 압력은 식 (7)과 식 (8)은 이용해서 구하며 이 매 $\mathrm{n}_{11}$ 는 식 $(6)$ 은 이용해 구할 수 있다. 즉. 압훅 선의 $\mathrm{NO}_{2}$ 와 $\mathrm{N}_{2} \mathrm{O}_{4}$ 의 놀수 $\mathrm{n}\left(\mathrm{NO}_{2}\right)$ 와 $\left.\mathrm{n}\left(\mathrm{N}_{2} \mathrm{O}_{1}\right)\right)_{1}$ 글 각각 0.000533

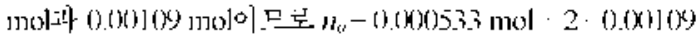
$\mathrm{mol}-0.00271 \mathrm{~m} 0 \mathrm{l}$ 이 독느나. 각 상태에서의 조성을 계산 한 격과는 Tahle 5 에 정러하었나.

Cher 는 곡음파 홉수 빙법(supersonic absorption nethod) 를 이용하여 2 $2 \mathrm{NO}_{2} \rightleftarrows \mathrm{N}_{2} \mathrm{O}_{4}$ 계의 혁반응의 속도 상수 를 측정하었는데. $25^{\circ} \mathrm{C}$ 에서 $1.710^{\circ} \mathrm{s}^{-1}$ 론 매우 빠르제 진행됙나도 하었나. 정닌응인 $\mathrm{NO}_{2}$ 가 격합하는 빈응의

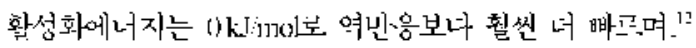
속고으. 상수와 $\mathrm{K}_{\mathrm{j}}$ 값을 이홍하여 25 "C에서의 이완시간

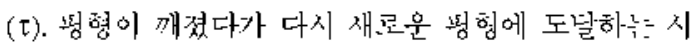

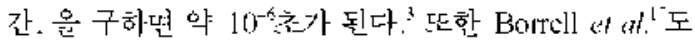
laser pulse photolysis 실힘에서 다 데략 $10^{-6}$ 츠세가 된 나그 하였나.

다 10 "초 정너로 매웅 짧 은 것을 각안하면 압축 직 후에 압려에 의힌 평형 이동과 온너능 상승에 의한 컹형 이동이 완결뇌었다고 볼 수 있다. 마라서. Table 5 에서 초기 평형 상태와 합축 식후의 조성을 비교해너떤 $\mathrm{NO}_{2}$

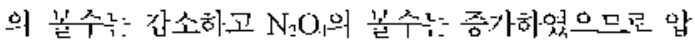
훅 직후에는 $\mathrm{N}_{2}\left(\mathrm{O}_{1}\right.$ 쏙(발열 빈응)으ㄹㅗㅗ 컹형 이동이 일어났 으며, 이것은 공기를 압축할 때 보나 $2 \mathrm{NO}_{2} \longrightarrow \mathrm{N}_{2}()_{4}$ 계 를 압훅했을 때 온고으. 상승폭이 너 커게 나타난 격롸와 일

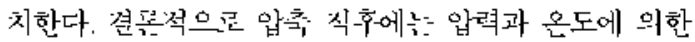
평형 이퐇이 겅생관계에 있는-데. 압력에 의한 효과 $\mathrm{N}_{2} \mathrm{O}_{1}$

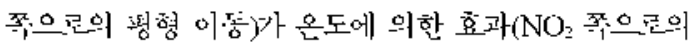
평형 이동)보나 커나고 핚 수 있나. 한편, 압러과 온-1ㅇㅇㅔ 의한 호과를 이론적인 계산을 봉해 그 커기를- 비교해 볼

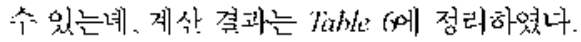

우선 압축; 식휘에 온도는 변하지 않고 부피만 1 2로 갑소한다고 가싱하년 이매 NO의 놀수는: 최홍 형형상 태와 같음 $3.8910^{-1} \mathrm{~mol}$ 이 되므룰 $1.4410^{-4} \mathrm{~mol}$ 의 $\mathrm{NO})_{2}$ 긲소가 생긴다. 빈면 압려이 일정힌 상태에서 신
Table 6. P'ressure and temperature dependence right aller conpression

\begin{tabular}{lc}
\hline \hline Condition & mol, ol $\mathrm{NO}_{2}$ \\
\hline Initial state & $5.3 .3 \cdot 10^{-4}$ \\
Compression to hall & $3.8910^{-4}$ \\
Temperalure rise by $5.2 \mathrm{~K}$ & $6.110^{-4}$ \\
\hline
\end{tabular}

험에서와 같이 $5.2 \mathrm{~K}$ 의 온도 싱승이 일어난다고 가징하 뎐 NO의 놀수는 $6.11 \quad 10^{-4} \mathrm{~mol}$ 이 뇌므롣 $0.78 \quad 10^{-1}$ 롤 의 $\mathrm{NO}_{2}$ 증가가 싱긴다. 마라서. 압축 식휘에은 압력에

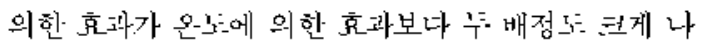
타난을 알 수 있나

온-1ㅡㅇㅇㅘ 압려에 내한 위 실험의 격과는 I.eenson이 $2 \mathrm{NO}_{2} \rightleftarrows \mathrm{N}_{2} \mathrm{O}_{4}$ 계의 압콕 과싱은 이상 기체의 단역 가 역 압혹 과싱으른 가싱하고. 예의 밥축 시에 계에 행해 진 믹이 읶부는 $\mathrm{N}_{2} \mathrm{O}_{1}$ 의 해레에. 나더.지는 계의 은도 상 응에 사용되는 것으오 하여 압훅 직후에 야 $1.3 \mathrm{~K}$ 정 5 의 온구승상승이 있을 것으로 에삼한 것롸는 차이가 있

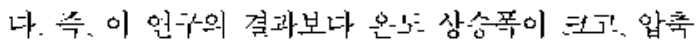

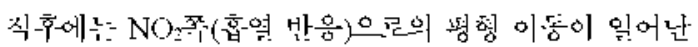
다는 섯을 의미하는-데. 이것은 Lecnson이 합혁 과침온 단역 가녁 과싱으로 가씽하었기 때넌에 싱겨난 차이롣

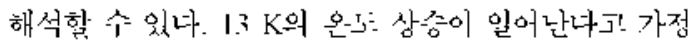
하커! 압축 적후의 초성을 계산해보면 N()의 몬수가 압 축 적에 비해 증가하는 결과가 나온나.

한편 계의 적갈색의 진하기를 결침하는 $\mathrm{NO}_{2}$ 의 부분 압은 비교해녀면 압혹 선의 $0.328 \mathrm{~atm}$ 에 비해 최총 평 형 상태에서 0.478 atm으롣 디 크므론 압축 선에 비해 압훅 후에 적각색이 너 직하나는 것을 알 수 있나. 따라 서. $2 \mathrm{NO}_{2} \longrightarrow \mathrm{N}_{2}\left(\mathrm{O}_{4}\right.$ 계의 압축 시에 평혐 이동에 의한 $\mathrm{NO}_{2}$

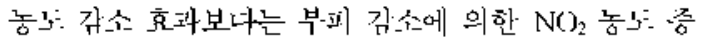
가 효과가 데 크다고 할 수 있다.

\section{실험 방법의 개선의 결과 및 논의}

앖의 격과에서 불 숭 있칫이 $2 \mathrm{NO}_{2} \longrightarrow \mathrm{N}_{2}\left(\mathrm{O}_{1}\right.$ 계의 압 


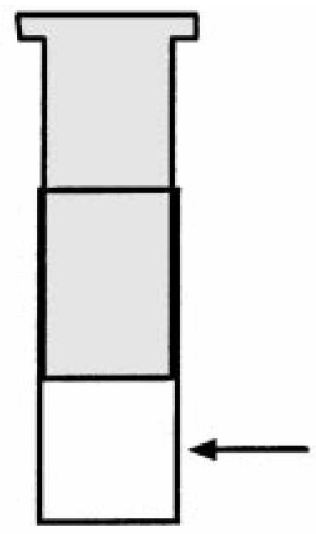

(a) side view

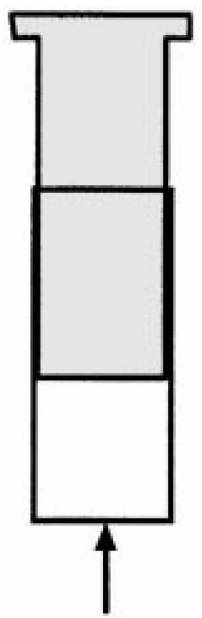

(b) front view
Fig. 6. Vien direction lor the color change.

Tabk 7. lihe change of lux betore and alter compression from Iront views

\begin{tabular}{cc}
\hline \hline Belore & Alter \\
\hline 84 & $95 \cdots 97$ \\
\hline
\end{tabular}

축 시 부피 갑소에 의한 $\mathrm{NO}_{2}$ 낭도 증가 효과가 압력에 따론 펑형 이동에 의한 $\mathrm{NO}_{2}$ 농노를 갂소 호과보나 커기 때문에 기쏜의 낭법대로 촉면에서 관칠하면 에상과는 닌내로 적각식이 신해지는 결과가 언어신나. 따라서. 이 연구에서는 $2 \mathrm{NO}_{2} \rightleftarrows \mathrm{N}_{2} \mathrm{O}_{4}$ 계의 압촉 시 압축하는 방 향으로 좐찬하면 누피 간소에 마른 $\mathrm{NO}_{2}$ 낭도 증가가 색깔 년화에 미치는 영햠운 내제하고 순수한 횡형 이동 에 의한 색낀 변화를 관찰핚 수 있나는 점에 칙안하여

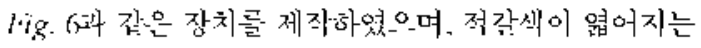
결과롤 유안으으로 관칠핚 수 있었나

뜨한. 색깔 년화를 싱향적으로 늑싱하기 위해 Fig. 6 콰 같응 장치를 제작하여 조도 년화를 륵싱하였으며 - -1 견과는 Toble 과 같다.

에상했년 마와 긱이 촉면에서 관칠했을 때는 II/8 Iux 에서 93 lux로 초느. 갂소가 있었으나 압축하는 방향에 서 관칠했을 때는 폰ㄱㄱ 가 84 lu에서 96 lux로 증가 측. 적잘색이 엷어지논 견과를 얻을 수 있었다. 마라서. 이 연구에서 개선한 실험 방법을 이욤하면 $2 \mathrm{NO}_{2} \rightleftarrows \mathrm{N}_{2} \mathrm{O}_{1}$ 계의 압력에 마른 평형 이동 현상을 색깔 년화론 관찰 하포 ㄴㅟㅟㄱㅔ 섞병핚 수 있을 것이나.

\section{요약 및 결론}

과학 교육에서 탑구활동이나 시범 실힘은 반드시 핀 요한 교수학습 과정이지만 교과시에 제시된 담구 과싱 이나 견과에 오류가 있기나. 낟당하는 교사가 살꼿된

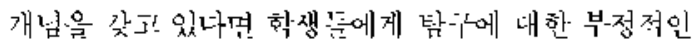

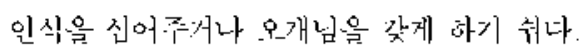

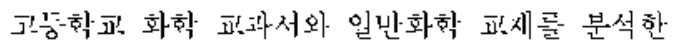
견과. $2 \mathrm{NO}_{2} \rightleftarrows \mathrm{N}_{2} \mathrm{O}_{4}$ 계를 압훅할 때 압축 선에 비 해 압훅 후의 색깔이 멃어지년 것으론 실험 결과를 쌀봇 기술하고 있고. 압축 씩후에 적갈색이 진해지는 것은 북피 갂스에 의한 $\mathrm{NO}_{2}$ 농놀 증가로, 적갉식이 나시 엷어지는 것은 압려에 의한 컹형 이동으로 해 석하고 있었나.

-프리나 이 연구 견과에 마르띤. 우선 $2 \mathrm{NO}_{2} \rightleftarrows \mathrm{N}_{2} \mathrm{O}_{4}$ 계의 압촉 시 부피 간소에 의한 NO는동도 증가 효과가 덩헝 이퐁에 의한 $\mathrm{NO}_{2}$ 농도 감소 효과녀다 크기 대눈 에 표과서 내숭과는 빈내로 적갖식은 신해지는 것으로 나타났나. 이러한 결과는 신제 탂다 확동을 하는테 있 어서 표사와 학생 모눟에게 많은 혼란을 가져온나. 따 라서. 이 연구에서논 이레한 눈제심은 해결하기 위해 실험 빙법은 개선하여 적갈색이 엮어지는 견과를 얻은 수 있었다. 족. 기존의 실혐서에 제시된 방멉은 계의 압 축 시 측면에서 관칠하기 때문에 적각새의 진하기에 엉

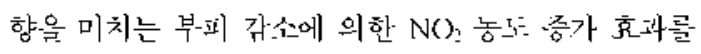
배제할 수 없지난, 압축하는 방향에서 관찰하게 되면 부피 갑소 효과를 내제한 수 있어. 헝헝 이동에 의한 적 갈색의 년화만은 관찬할 수 있다.

뜬한 계의 압촉 식후에 적갈색이 진해지는 현상을 해 석하는뎨 있어서는 북피 각스뿐반 아니라 온노르 상승에

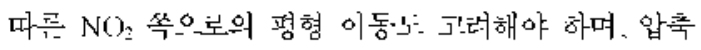
직후 적각식이 칙해졌나가 나시 엷어지는 헌삼은 기촌 의 내용처런 압력에 의한 헝헝 이동이 아니라 가열되었 던 계가 넹각되던서 익어나는 온도에 의한 횡헝 이동으 론 버아야 할 섯이다.

따라서, 제6차 피과서에 잔못 기순뎩! 내옹의 수정이

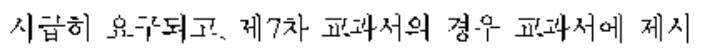
됙! 신헌을 나론 신형으로 표!체하거나. 이 언구에서 개 선한 방법으론 대체할 횐요가 있다고 생각되며. 고등학 교 교사들도 $2 \mathrm{NO}_{2} \rightleftarrows \mathrm{N}_{2} \mathrm{O}_{1}$ 계에 압력은 가할 때 읶어 나느: 현상에 대해 침학한 인식을 갖는: 것이 닐요하다고 생각힌나. 


\section{인 용 문 헌}

1. Finely. F. N.: Stewart. J.: Yorroch. W. L. Sci. Eahe: $1982,66(4) .531$.

2. Yang. 7. J. ('hem. Fith 1993. 70(2). 94.

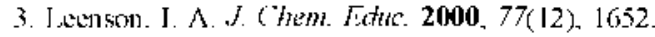

4. Shakbashiri. B. 7.. Chemical Demonstrations, id Itohdbook for Teachers of (hemistry: The University of Wisconsin Press: Wisconsin. U.S.A. 1985: Vol. 2. p 167.

5. Athins. P. W. Genend Chemistry Intemational Sthdent Ed: Sciontitic American Books: New York., IJ.S.A. 1989: p 500.

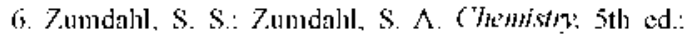
Jioughton Miftlin Company: New York. UJ.S.A. 2000: p 643 .

7. Brown. 1. L.: Lemay Jr.. H. E.: Bursten. B. E. Chemistr?: 81h ed: Prentice Hall Intemational Inc.: New
Jerser: U.S.A., 2000: p 573.

8. Sangster. $\wedge$. W. J. (hem. Edic. 1959, 36, 159 .

9. Sutton. Г. C. (Whistry 1972. $45(1) .28$.

10. I Jerron. J. D. J. Chem. Edhc. 1976. 53(6), 374.

I1. Kang. F.-G. Un published Master Dissertation: Korea National University of Education: Chunguk. Korea. 2003.

12. Gray, P.: Yolte. A. D. Chem. Run 1955, 55. 1069.

13. Roscoe. H. K.: Hind. A. K. J. flmos. Chem 1992. 16(3). 257 ,

14. Chao. J.: Wilhoit. R. C.: Zwolinsti. B. J. Themochm. fcta. 1974. 10.359.

15. Vosper. A. I. J. Am. Chem. Sok 1970. $325(\mathrm{~A}) .625$.

16. Cher. M. J. Chem. Phos. 1962. 37. 2564.

17. Bonel. P': Cobos. C, J.: Luther. K. J. Fhus. (Thm. 1988. 92(15). 4377 . 